\title{
Sin Tax Law Attributes on the Buying Behavior, Smoking Habits and Academic Performance of Students
}

\section{Ken N Falculan}

Faculty, College of Agriculture, Romblon State University Odiongan, Romblon 5505 Philippines

\begin{abstract}
This study was conducted to determine the attributes of Sin Tax Law on the buying behaviors and academic performance of RSU students with smoking habits. It utilized the descriptive method of research in analyzing data and it uses the purposive sampling technique to determine the attributes of sin tax law to the buying behaviors and academic performance of students. Results drawn were number of students who smoked are between ages of 18-19 years old. Most of the respondents are male. Males smoked cigarettes more frequently than female. Majority of the respondents had a general weighted average of 1.752.25. Respondents are aware of on the Sin Tax Law an act restructuring the excise tax on alcohol and tobacco products. The Law significantly affect the buying behavior of the respondents. The prevalence of smoking among college students decreases. Level of awareness of students on Sin Tax Law has significant relationship with their buying behaviors. In addition, the academic performance of the students is not affected by the level of awareness, buying behavior and smoking habits. The implementation of this law must be strictly imposed by the local government and the academe to help in decreasing or even stopping in consumption of cigarettes among college students and to all smokers in the community.
\end{abstract}

KEYWORDS: Academic Performance, Buying Behavior, Sin Tax Law, Smoking Habits

\section{INTRODUCTION}

The Philippines was the $15^{\text {th }}$ largest consumer of cigarettes in the world and currently has one of the highest smoking rates in Asia, as well as some of the lowest cigarette prices. The Philippines ranks second in number of smokers, and has the highest number of female smokers in the 10 members of Association of Southeast Asian Nation. World Health Organization, (2009). In fact, in the Western Pacific Region our country is one of the largest consumers of tobacco.

Smoking is the method of consuming tobacco, the most common substance smoked. Tobacco use has remained high for many years and significant numbers of Filipino youth are smokers, especially students. And the usual factor leading them to smoke is cigarette advertisement. Smoking by parents, siblings, and friends also encourage them to smoke.

Smoking is viewed by some students that it reduces anxiety and it often occurs after stressful events or stressful situations. Also, as a way to socialize and take study breaks. Cigarette smoking became one of the highly sought after vice in the Philippines because of the affordable price of each stick ranging from seventy-five to two pesos each, depending on its brand. It is observably one of the reason why consumption of cigarettes among Filipinos increases. That's why the Philippine Government came up with the idea of increasing the taxes imposed upon alcoholic beverages and cigarette sticks in order to minimize its harmful effects to human body. The Republic Act 10351, also known as the "Sin Tax Law" which provides for additional tax on sin products such as alcohols and tobacco products.

The rise in cigarette prices brought about by higher sin taxes was one of the primary reason why a slight reduction in youth smoking prevalence occurred. In the light of its indicator, they confidently uphold their assessment that the sin tax law is proving itself to be an effective smoking reduction measure. With higher cigarette prices, long addicted Filipino tobacco users are lessening their consumption, while would- be smokers, especially from the young and the poor, are increasingly discouraged from taking up smoking in the first place. Youth Adult and Fertility and Sexual Study, 2013) among the smokers. Though sin tax law proved that it has an impact to lessen the consumption of cigarette among the smokers, no studies have been conducted to assess the attributes of sin tax law to the buying behavior of the students with smoking habits in Romblon State University.

As a concerning problem on the health of students exposed in smoking, the researcher encourages to conduct a study that determine the attributes of sin tax law to the buying behavior of the students, smoking habits and academic performance in Romblon State University, 


\section{Sin Tax Law Attributes on the Buying Behavior, Smoking Habits and Academic Performance of Students}

\section{STATEMENT OF THE PROBLEM}

The study aim to determine the attributes of Sin Tax Law on the buying behaviors and academic performance of RSU students with smoking habits. The study sought to answer the following questions:

1. What is the level of awareness of the students on the Sin Tax Law?

2. What is the academic performance of the respondents in terms of their General Weighted Average?

3. What are the effects of Sin Tax Law to the buying behavior of the students?

4. What is the smoking habits affecting the academic performance of the students?

5. Is there significant relationship between the level of awareness of the students on the Sin Tax Law and their buying behavior?

6. Is there a significant relationship between smoking habits and their academic performance?

\section{METHODOLOGY}

The study utilized the descriptive method of research. Calmorin and Calmorin (2007) are appropriate wherever the objects of any class vary among themselves and one is interested in knowing the extent to which different condition altering among these subjects. The purpose of descriptive method is to find new truth which comes in different form such as increases in sight into factors which are operating the discovery of a new causal relationship, a more accurate formulation of the problems to be solved and the like. Further, the descriptive method of study emphasize what actually existed in current conditions during the conduct of the research. It involves the collection of data in order to answer questions concerning the status of the study.

\section{SUBJECT OF THE STUDY}

The subjects of the study were the students with smoking habits in Romblon State University, Odiongan, Romblon.

\section{POPULATION OF THE STUDY AND SAMPLING TECHNIQUE}

The researcher used purposive sampling technique to determine the sample. Purposive sampling reflects a group of sampling techniques that rely on the judgment of the researcher when it comes to selecting the units to be used on the study.

\section{DATA GATHERING INSTRUMENT}

The research instrument composed of three parts. Part I includes question for the awareness of the students on the Sin Tax Law. For their responses, respondents were given the five (5) point rating scale and the corresponding verbal interpretation:

\begin{tabular}{lll}
\hline Raw Score & Range Score & Verbal Interpretation \\
\hline 5 & $4.21-5.00$ & Very much aware \\
4 & $3.41-4.20$ & Aware \\
3 & $2.61-3.40$ & Neither aware nor unaware \\
2 & $1.81-2.60$ & Unaware \\
1 & $1.00-1.80$ & Very much unaware \\
\hline
\end{tabular}

Part II is about the attributes of Sin Tax Law on the buying behavior. And lastly, Part III is about the effects of smoking on the academic performance of the students. With the same rating scale, the respondents were instructed to choose from the choices as follows:

\begin{tabular}{lll}
\hline Raw Score & Range Score & Verbal Interpretation \\
\hline 5 & $4.21-5.00$ & Very much agree \\
4 & $3.41-4.20$ & Agree \\
3 & $2.61-3.40$ & Neither agree/ disagree \\
2 & $1.81-2.60$ & Disagree \\
1 & $1.00-1.80$ & Very much disagree \\
\hline
\end{tabular}

\section{DATA GATHERING PROCEDURE}

The researcher uses the questionnaire as a tool for student's respondents. The questionnaire was distributed through hand carry and collected after they have finished answering. The respondents are given ample time to analyze to enable them make decision properly. All items in the questionnaire were treated confidential in nature.

\section{DATA PROCESSING AND STATISTICAL ANALYSIS}

The following were used to analyzed, summarized and interpret the data gathered. 
Sin Tax Law Attributes on the Buying Behavior, Smoking Habits and Academic Performance of Students

\section{Variables}

1. To determine the level of awareness of the students on the Sin Tax Law

2. To determine the general weighted average of the grades of students

3. Buying behavior of the respondents

4. Smoking habits of respondents

5. Relationship between the level of awareness of the respondents on the Sin Tax Law and their buying behavior

6. Relationship between the smoking habits of the respondents and their academic performance

\section{Statistical Tool}

Weighted Mean, Verbal Interpretation

Weighted Mean, Frequency, Percentage

Weighted Mean, Verbal Interpretation

Interpretation

Person Product-Moment Correlation

Person Product-Moment Correlation

\section{RESULT AND DISCUSSION}

\section{Demographic profile of the respondents.}

The distribution of the student-respondents according to their age, sex and general weighted average. The population of the respondents indicates that $43.55 \%$ were smokers and ranges on the ages of $18-19$ years old. The $23.12 \%$ belong to $20-21$ and $21.51 \%$ belong to 16-17 years old respectively. The respondents from 22 to 29 years old had the least number of smokers which has $11.84 \%$.

In terms of gender attributes, male has a total of $69.89 \%$ and female has $30.11 \%$ in smoking population. Male smoked cigarettes more frequently rather than female. It is similar from the Global Adult Survey (2009) based on the data male are more likely use tobacco products rather than female. Majority of the students had a general weighted average of 1.75-2.25. The $17.14 \%$ of the students had a general weighted average of 2.5-3.0. Respondents having a general weighted average of 1.0-1.5 are 3.76\%. It shows a positive relationship between smoking and academic achievements. This means students who engaged in smoking received higher grades. This finding is different from the result of the study conducted by the national Youth Risk Behavior Survey (2009), they found out that student who more likely to smoke cigarette had lower grades than those who less likely to engaged in smoking.

Table 1. Demographic profile of the respondents

\begin{tabular}{lll}
\hline Profile & Frequency & Percentage \\
\hline Age (years) & & \\
$16-17$ & 40 & 21.51 \\
$18-19$ & 81 & 43.55 \\
$20-21$ & 43 & 23.12 \\
$22-23$ & 14 & 7.53 \\
$24-25$ & 4 & 2.15 \\
$26-27$ & 1 & 0.54 \\
$28-29$ & 3 & 1.62 \\
\hline Total & $\mathbf{1 8 6}$ & $\mathbf{1 0 0}$ \\
\hline Sex & & \\
Male & 130 & 69.89 \\
Female & 56 & 30.11 \\
\hline Total & $\mathbf{1 8 6}$ & $\mathbf{1 0 0}$ \\
\hline General Weighted Average & & \\
$1.0-1.5$ & 7 & 3.76 \\
$1.75-2.25$ & 146 & 78.49 \\
$2.5-3.0$ & 33 & 17.74 \\
\hline Total & $\mathbf{1 8 6}$ & $\mathbf{1 0 0}$ \\
\hline
\end{tabular}

\section{Students Level of Awareness on Sin Tax Law}

The findings in terms of respondent's level of awareness on sin tax law are shown in table 2 reveals that the respondents are aware that Republic Act No. 10351 also known as Sin Tax Law of 2012 and this law is an act restructuring the excise tax on alcohol and tobacco. Its purpose is to reduce the consumption of tobacco and alcohol beverages. They are also aware that the sin tax law was signed on December 20, 2012. In the statement, that this law took effect on January 1, 2013 findings shows that some of the respondents are neither aware nor unaware on that statement it had a mean of 3.38. All in all, findings shows that majority of the respondents are aware of the Law. 


\section{Sin Tax Law Attributes on the Buying Behavior, Smoking Habits and Academic Performance of Students}

Table 2. Students Level of Awareness on the Sin Tax Law

\begin{tabular}{lll}
\hline Statement & Mean & Verbal Interpretation \\
\hline $\begin{array}{l}\text { Republic Act No. 10351 also known as Sin Tax Law. } \\
\text { Sin Tax Law of 2012 is an act restructuring the excise tax on alcohol } \\
\text { and tobacco. }\end{array}$ & 3.66 & Aware \\
$\begin{array}{l}\text { Purpose of Sin Tax Law is to reduce the consumption of tobacco and } \\
\text { alcoholic beverages }\end{array}$ & 3.71 & Aware \\
$\begin{array}{l}\text { Sin Tax Law was signed on December 20, 2012 } \\
\text { Sin Tax Law took effect on January 1, 2013 }\end{array}$ & 2.47 & Aware \\
\hline Average weighted Mean & 3.38 & Neither aware nor unaware \\
\hline
\end{tabular}

\section{Buying Behaviors of the Respondents}

The respondents of the study were agreed that before Sin Tax Law was implemented, they frequently smoked cigarettes everyday but after this law was implemented respondents revealed that they smoked $\leq 5$ stick of cigarettes per day. This means during the time that the price of cigarettes are in a low price the respondent smoked more than 5 sticks or sometimes one pack of it are consumed in a day, but after the prevailing of higher prices of cigarettes their buying habits decreases. The respondent's consumption of cigarettes per day in present time became $\leq 5$ five sticks. With the mean of 3.45 the respondents were agreed that they felt less peer pressure on buying cigarette since the Sin tax law was implemented. Also, they neither agreed nor disagreed that after the increase in price of cigarettes they choose to shift to a cheaper brand instead of giving up on smoking. Undecidedly, the increase in price of cigarettes discouraged them to smoke. These findings shows that the Sin Tax Law took effect on the buying behavior of the respondents. The prevalence of smoking among students decreases.

Table 3. Smoking behavior toward smoking of respondents.

\begin{tabular}{|c|c|c|}
\hline Statement & Mean & Verbal Interpretation \\
\hline I frequently smoke everyday & 3.49 & Agree \\
\hline Before the implementation of Sin Tax Law I smoke $\geq 5$ sticks everyday. & 3.54 & Agree \\
\hline $\begin{array}{l}\text { I feel less peer pressure on buying cigarettes since sin Tax law was } \\
\text { implemented. }\end{array}$ & 3.94 & Very much agree \\
\hline $\begin{array}{l}\text { After the increase in the price of cigarettes, I choose to shift to a cheaper } \\
\text { brand instead of quitting on smoking. }\end{array}$ & 3.27 & $\begin{array}{l}\text { Neither Agree nor } \\
\text { Disagree }\end{array}$ \\
\hline The increase in the price of cigarette discourage me to smoke. & 2.99 & $\begin{array}{l}\text { Neither Agree nor } \\
\text { Disagree }\end{array}$ \\
\hline Average Weighted Mean & 3.45 & Agree \\
\hline
\end{tabular}

\section{Smoking Habit of the Student-respondents}

The findings in terms of smoking habits of respondents are shown in table 4. The result indicates that in terms of their habits they agreed that when they are tense or upset they smoked and they are more likely to smoke if they feel anxious or uncomfortable. Also, they smoke only in areas where smoking is allowed. The result is similar to the article of Fiala et.al., (2010) who stated that one of the reasons that college students smoke is that it offers them pleasure, relaxation and tension reduction. Same with the result on the study of Battista et.al., (2008) smokers with high levels of anxiety sensitivity personality trait, especially those with psychological concern about the consequences of anxiety, are motivated to smoke to relieve aversive state or to achieve pleasurable states. Respondents are neither agreed nor disagreed that they more likely to smoke with their circle of friends or peers while drinking and there is a portion of their allowance that is always allocated for buying cigar. They prefer to smoke before going to school and more likely to smoke while studying. According to the respondents sometimes they tend to smoke more than attending the class and to escape during class hour.

Table 4. Smoking habits of the student- respondents

\begin{tabular}{lll}
\hline Statements & Mean & Verbal Interpretation \\
\hline I tend to smoke more than attending the class & 2.68 & Neither agree nor disagree \\
When I am tense or upset I smoke & 3.54 & Agree \\
I am more likely to smoke if I fell anxious or uncomfortable & 3.70 & Agree \\
I am more likely to smoke while studying & 2.94 & Neither agree nor disagree \\
I prefer to smoke before going to school. & 3.11 & Neither agree nor disagree \\
I only smoke in areas where smoking is allowed. & 3.65 & Agree
\end{tabular}




\section{Sin Tax Law Attributes on the Buying Behavior, Smoking Habits and Academic Performance of Students}

I am more likely to smoke with my circle of friends or peers. $\quad 3.21$

Smoking tends to cause me to escape during class hour.

$3.21 \quad$ Neither agree nor disagree

2.64 Neither agree nor disagree

There is a portion of my allowance that is always allocated for 3.15

Neither agree nor disagree

buying cigarettes.

I prefer smoking while drinking.

3.24 Neither agree nor disagree

\begin{tabular}{lcl}
\hline Average Weighted Mean & 3.29 & Neither agree nor disagree \\
\hline
\end{tabular}

Relationship of Grade to the Extent of Doing the Smoking Habits and the Respondent's Level of Awareness on The Sin Tax Law and their Buying Behavior

Pearson Correlation test shows that there is no significant relationship between academic performance and student's level of awareness on the Sin Tax Law as implied by the P-Value 0.305. This value leads to the decision of accepting the null hypothesis. It also shows that there is no significant relationship between academic performance and buying behavior with R-value of 0.022. Based on the statistical analysis the grades of the respondents have no significant relationship to the extent of doing the smoking habits with P-value 0.903 indicates the acceptance of the null hypothesis. (Table 5)

Table 5. Relationship of Grade to the Extent of Doing the Smoking Habits and the Respondent's Level of Awareness on the Sin Tax Law and their Buying Behavior

\begin{tabular}{lllll}
\hline Dependent & Independent & r- value & P-value & Relationship \\
\hline Academic Performance & Level of Awareness & 0.076 & 0.305 & Not Significant \\
& Buying behavior & 0.022 & 0.770 & Not Significant \\
& Smoking Habits & 0.009 & 0.903 & Not Significant \\
\hline
\end{tabular}

\section{CONCLUSION}

The respondent's level of awareness on the Sin Tax Law cause significantly on the buying behaviors. In addition the academic performance of the students-respondent's is not affected by the level of awareness, buying behavior and smoking habits.

\section{DEDICATION}

This humble peace was dedicated to Our Lord Almighty for His Grateful Guidance, to my Family, Co-workers, respondents who inspired the researcher. To all of you, whatever hindrances and sorrows we encountered in our life.... always remember that life is full of Love and Wisdom.

\section{REFERENCES}

1) S.R. Battista, S.H. Stewart, H.G. Fulton, D. Steeves, C. Darredeau, \& D. Gavric. A Further Investigation of the Relations of Anxiety Sensitivity to Smoking Motivates. Addictive Behaviors, 33(11), 1402-1408, 2008. Retrieved from: http://dx.doi.org/10.1016/j.addbeh.2008.06.016

2) L. Calmorin and M.A. Calmorin. Methods of Research and Thesis Writing. Rex Bookstore Inc, 2007.Manila, Philippines

3) K.A. Fiala, M.L. D'Abundo, L.M. Marinaro. Construct validity and reliability of College Students Responses to the reasons for smoking scale. Journal of American College Health. 58(6). Retrieved from:

http://www.inderscienceonline.com/doi/full/10.1504/IJBHR.2012.045620

4) Global Adult Tobacco Survey. "17.3 Million Filipino Adults Are Current Tobacco Smokers", 2009. Retrieve from; https;//psa.gov.ph/article/173-million-filipino-adults -are-current-tobacco-smokers.

5) A. Macaraig. After 15 years, sin tax bill hurdles Senate, Rappler, 2012. Retrieved from: http://www.rappler..com/business/16480-after-15-yrs,-sin-tax-billhurdles-senate

6) National Youth Risk Behavior Survey. Tobacco Use and Academic Achievements, 2009. Division of Adolescent and School Health. Retrieved from: http://www.cdc.gov/healthyyouth/health_and_use.pdf

7) Hye-Jin Paek. Different Effects of Different Peers. Further Evidence of the Peer Proximity Thesis in Perceived Peer Influence on College Students' Smoking. Journal of Communication, 59(3), 2009. Retrieved from: www.onlinelibrary.wiley.com

8) E. Sunley. Taxation of Cigarettes in the Bloomberg Initiative Countries: Overview of Policy 1 Issues and Proposal for Reform. Report submitted to the Bloomberg Initiative to Reduce Tobacco Use under a contract from the International Union Against Tuberculosis and Lung Disease. Retrieved from: http://tobaccofreecenter..org/files/pdfs/en/Cigarette_tax_Blcountries.pdf

9) K. Water, K. Harris. Characteristics of Social Smoking among College Students, Journal of American College Health, 55(3), 2006. Retrieved from: www.tandfonline.com 
Sin Tax Law Attributes on the Buying Behavior, Smoking Habits and Academic Performance of Students

10) J.M. Wolburg. College Students Responses to Anti-smoking Messages: Denial, Defiance, and other Boomerang Effects, Journal Consumer Affairs, 40(2), 2006. Retrieved from: www.onlinelibrary.wiley.com

11) World Health Organization (WHO). The Advent of Smoking in the Philippines, 2009. Retrieved from: http://pjfiles.wordpress.com/2011/10/18/the-advent-of-smoking-in-the-philippines/

12) Youth Adult and Fertility and Sexual Study (YAFS). Tobacco Use and Academic Achievement, 2009. Retrieved from: http://www.cdc.gov/healthyyouth/health_and_academics/pdf/tobacco_use.pdf 